\title{
DESAIN JARINGAN DRAINASE DESA GANDANG BARAT KECAMATAN MALIKU KABUPATEN PULANG PISAU
}

\author{
Tahan \\ Program Studi Teknik Sipil, Fakultas Teknik, Universitas Kristen Palangka Raya \\ E-mail: utuntahan10@gmail.com
}

\begin{abstract}
ABSTRAK
Daerah rawa di Indonesia mempunyai lahan seluas 39.424 .500 hektar.Jumlah rawa Pasang surut di Kabupaten Pulang Pisau 9.063.000 hektar, di Kecamatan Maliku 350.000 hektar. Daerah rawa di Pangkoh V dan VI dibangun pada Tahun 1983 meliputi jaringan drainase saluran primer sepanjang $27 \mathrm{~km}$ saluran Sekunder sepanjang $599 \mathrm{~km}$, dan selesai pada tahun 1985 dengan luas areal 9246 hektar. Pada tahun 1985 transmigrasi di datangkan dari luar kecamatan, Sebagian dari penduduk Kalimantan Tengah dengan tujuan memanfaatkan lahan rawa yang ada. Dengan kondisi saluran sekunder di daerah Desa Gandang Barat Kecamatan Maliku Kabupaten Pulang Pisau. yang tidak berfungsi oleh sebab itu sejak tahun 2005, 2010, 2016 sampai 2019 terjadi banjir yang cukup dalam $\pm 70 \mathrm{~cm}$, oleh karena itu perlu adanya desain jaringan Irigasi. Secara umum penelitian di lakukan dalam beberapa tahap,yaitu: pengumpuan data, analisis data, evaluasi kapasitas, dan desain sistem drainase. Jenis data yang dikumpulkan sebagai bahan analisis adalah data sekunder dan data primer. Data sekunder berupa peta, data curah hujan bulanan dan beberapa data lainnya. Disamping untuk analisis, data sekunder tersebut juga akan dijadikan pedoman dalam pengumpulan data primer. Data primer yang dikumpulkan anatara lain perhitungan curah hujan dengan cara normal, log normal, log pearson III, dan Gumbel. Dari perhitungan curah hujan data Gumbel yang paling akurat, sehingga dijadikan pedoman dalam perhitungan profil memanjang dan melintang saluran. Untuk menentukan debit drainase rencana (Qr) dan besaran kapasitas pengaliran drainase (Qs). Jika Qr > Qs akan dilakukan perencanaan ulang terhadap kapasitas pengaliran. Besarnya volume debit air pada sistem jaringan drainase yang dialirkan melalui saluran sekunder umur rencana 5 tahun $\left(\mathrm{X}_{\mathrm{TR}}=5\right.$ Tahun $)$ dengan menggunakan distribusi probalitas Gumbel adalah 135,95 mm, intensitas curah hujan 45,45 mm/jam.Pembuatan 25 saluran yang baru tidak perlu dan normalisasi 24 saluran yang lama dengan ketinggiaan air $1,70 \mathrm{~m}$ dari dasar saluran sudah cukup untuk mengatasi limpahan air pasang dari saluran PLG 1 juta hektar, 135,95 mm curah hujan. Dan ini dapat menghindari terjadinya banjir lagi dengan ketinggian $\pm 0,70 \mathrm{~m}$. Adapun luas yang digenangi banjir pada saat ini berkisar \pm 320 hektar. Perencanaan saluran sekunder diambil debit aliran perhitungan yang terbesar yaitu $\mathrm{Q}=19,39 \mathrm{~m}^{3} / \mathrm{dt}>\mathrm{Qr}$ (Debit drainase rencana kumulatif $=2,286 \mathrm{~m}^{3} / \mathrm{dt}$ ). Untuk memaksimalkan kapasitas 24 saluran drainase yang sudah ada, maka perlu dilakukan pemeliharaan saluran dengan cara membersihkan sampah dan tumbuhan pengganggu, serta memperdalam ketinggian air drainase setinggi $1,70 \mathrm{~m}$ secara berkala. Adanya hubungan yang sinergis antara masyarakat, swasta, dan pemerintah juga sangat berpengaruh terhadap berfungsinya sistem drainase yang baik.
\end{abstract}

Kata Kunci : Desain, Jaringan, Drainase, Metode, Analisa, Dimensi, Irigasi, Debit air Dan Evaluasi.

\author{
ABSTRACT \\ Indonesia has about 39,424,500 hectares of swamp areas. In Pulang Pisau district, it is \\ found about 9,063,000 hectares of tidal swamp areas, and in Maliku District alone has
}


350,000 hectares. The swamp areas in Pangkoh V and VI was started built in 1983 covering a $27 \mathrm{~km}$ long primary drainage network and $599 \mathrm{~km}$ long secondary canals and then completed in 1985 with an area of 9,246 hectares. In 1985 transmigration was carried in from outside the sub-district, some of whom were residents of Central Kalimantan with the specific aim of exploiting the existing swamps. With the condition of the secondary channel in Gandang Barat village, Maliku sub-district, in 2005, 2010, 2016 and 2019 there were floods that were quite deep, that was $\pm 70 \mathrm{~cm}$, and therefore a flood irrigation network design was needed. In general, the research was carried out in several steps, such as: data collection, dataanalysis, capacity evaluation, and drainage system design. The types of data collected as materialfor analysis are secondary data and primary data. Secondary data are maps, monthly rainfall dataand several other supporting data. In addition to analysis, secondary data will also be used as a guide in primary data collection. Primary data that will be collected include the calculation of rainfall in the normal way, normal log, Pearson III log, and Gumbel. From the calculation of rainfall, the Gumbel data is the most accurate, so that it is used as a guide in calculating the longitudinal and transverse profiles of the channel. To determine the planned drainage discharge(Qr) and the amount of drainage capacity (Qs). If $Q r>Q s$ will be redesigned the flow capacity.The volume of water released in the drainage network system that is channeled throughthe general secondary channel of the 5-year plan $(X T R=5$ years $)$ using the Gumbel probabilitydistribution is $135.95 \mathrm{~mm}$, rainfall intensity is $45.45 \mathrm{~mm} / \mathrm{hour}$. The construction of 25 newchannels is not necessary and normalization of the old 24 channels with a water level of $1.70 \mathrm{mfrom}$ the bottom of the channel is sufficient to overcome water runoff from the PLG channel 1million hectares, $135.95 \mathrm{~mm}$ of rainfall. And this can prevent flooding again with a height of $\pm 70 \mathrm{~cm}$. The area that was inundated at the time of the flood is currently \pm 320 hectares. Secondary channel planning takes the largest calculation flow rate, namely $Q=19.39 \mathrm{~m} 3 / \mathrm{s}>Q r$ (cumulative plan discharge $=2.286 \mathrm{~m} 3 / \mathrm{s}$ ). To maximize the capacity of the existing 24 drainage channels, it is necessary to maintain the canals by cleaning trash and nuisance plants and deepening the drainage water level to $1.70 \mathrm{~m}$ on a regular basis. The existence of a synergistic relationship between the community, the private sector and the government will also greatly affect the functioning of a good drainage system.

Keywords: Design, Drainage network, Method, Analysis,Ddimensions, Irrigation, Water Volume and Evaluation.

\section{PENDAHULUAN}

Daerah rawa di Indonesia mempunyai lahan seluas 39.424 .500 hektar. Selama ini tidak difungsikan sebagai pertanian dan perkebunan untuk kemajuan Ekonomi dan kemakmuran bangsa dan sekaligus mengurangi pengangguran. Jumlah rawa Pasang surut di Kabupaten Pulang Pisau 9.063.000 hektar, di Kecamatan Maliku 350.000 hektar. Daerah rawa di Pangkoh V dan VI dibangun pada Tahun 1983 meliputi jaringan drainase saluran primer sepanjang $27 \mathrm{~km}$ saluran Sekunder sepanjang $599 \mathrm{~km}$, dan selesai pada tahun 1985 dengan luas areal 92,46 km². Pada tahun 1985 transmigrasi di datangkan dari luar kecamatan, Sebagian dari penduduk Kalimantan Tengah dengan tujuan memanfaatkan lahan rawa yang ada. Dengan kondisi saluran sekunder di daerah Desa Gandang Barat Kecamatan Maliku Kabupaten Pulang Pisau. yang tidak berfungsi oleh sebab itu sejak tahun 2005, 2010, 2016 sampai 2019 terjadi banjir yang cukup dalam $\pm 70 \mathrm{~cm}$, oleh karena itu perlu adanya desain jaringan Irigasi. 


\section{METODE PENELITIAN}

Secara umum penelitian dilakukan dalam beberapa tahap, yaitu: pengumpulan data, analisis data, evaluasi kapasitas, dan desain sistem drainase. Jenis data yang dikumpulkan sebagai bahan analisis adalah data sekunder dan data primer. Data sekunder berupa hasil studi terdahulu yang terdiri dari peta, dan data curah hujan. Di samping untuk analisis, sebagian dari data sekunder tersebut juga akan dijadikan pedoman dalam pengumpulan data primer. Data primer yang dikumpulkan antara lain profil memanjang dan melintang saluran, dan kondisi sistem drainase. Analisis data antara lain dimaksudkan untuk mendapatkan besran debit drainase rencana (Qr) dan besaran kapasitas pengaliran drainase (Qs). Kemudian dilakukan perbandingan Qr dan Qs untuk mengetahui kapasitas pengaliran. Jika Qr> Qs, akan dilakukan perencanaan ulang terhadap kapasitas pengaliran. Debit Drainase Rencana dihitung dengan metode Rasional. Tahapan Perhitungannya adalah sebagai berikut: Debit Curah Hujan $\left(Q_{a h}\right)$ Penentuan luas daerah aliiran saluran/tangkapan hujan. Luas tangkapan hujan untuk masing - masing saluran ditentukan dengan memperhatikan faktor topografi dan curahh hujan dominan aliran. Curah hujan ranjanganCurah hujan wilayah yang diperoleh dari data curah hujan harian maksimum tahunan selama 5 tahun terakhir dan berasal dari stasiun Maliku Kabupaten Pulang Pisau dan digunakan sebagai data dalam menghitung curah hujan rancangan. Distribusi probabilitas yang digunakan adalah distribusi Normal, Log Normal, Gumbel dan Log Pearson Type III.Pengujian distribusi probabilitas hujan rancangan Curah hujan rancangan yang dihasilkan dengan distribusi Normal, log Normal, Gumbel dan Log Pearson Type III diuji kesesuaiannya dengan cara Chi-Kuadrat dan Smirnov-Kolmogorov (Triatmodjo, 2008). Keempat jenis distribusi yang diuji tersebut dipilih salah satu yang paling sesuai.

\section{HASIL DAN PERHITUNGAN}

Data curah hujan rencana adalah data curah hujan harian maksimum tahunan yang berasal dari stasiun Maliku Kabupaten Pulang Pisau. Data tersebut merupakan data curah hujan dengan periode pengamatan 5 tahun terakhir, yaitu dari tahun 2015 - 2019. Data curah hujan maksimum tahunan tersebut dapat dilihat pada Tabel 1 berikut ini :

Tabel 1. Curah hujan Harian Maksimun Tahunan

\begin{tabular}{|l|c|c|}
\hline No. & Tahunan & Curah Hujan Maksimum (mm) \\
\hline 1 & 2015 & 68,9 \\
2 & 2016 & 20,94 \\
3 & 2017 & 74,2 \\
4 & 2018 & 145,5 \\
5 & 2019 & 103,0 \\
\hline
\end{tabular}

Sumber : BMG Palangka Raya

\section{Perhitungan Curah Hujan Rencana}

Menghitung parameter statistik untuk menentukan jenis distribusi yang sesuai dengan data yang ada Perhitungan Parameter Statistik dilakukan dalam Tabel 2 
Tabel 2. Hitungan Parameter Statistik

\begin{tabular}{|l|c|c|c|c|c|c|}
\hline No & Tahun & $\begin{array}{c}\text { Curah Hujan } \\
\mathrm{x},(\mathrm{mm})\end{array}$ & $(\mathrm{Xi}-\bar{X})$ & $(\mathrm{Xi}-\bar{X})^{2}$ & $(\mathrm{Xi}-\bar{X})^{3}$ & $(\mathrm{Xi}-\bar{X})^{4}$ \\
\hline 1 & 2015 & 68,90 & $-13,608$ & 185,178 & $-2519,90$ & 34290,77 \\
2 & 2016 & 20,94 & $-61,568$ & 3790,619 & $-233380,807$ & 14368789,6 \\
3 & 2017 & 74,20 & $-8,308$ & 69,023 & $-573,442$ & 4764,156 \\
4 & 2018 & 145,5 & 62,992 & 3967,992 & 249951,756 & 15744961 \\
5 & 2019 & 103,0 & 20,492 & 419,920 & 8605,043 & 176334,54 \\
\hline \multicolumn{5}{|c|}{$\Sigma$} & 412,54 & \multicolumn{2}{|c|}{8432,732} & 22082,65 & 30329140,1 \\
& & & \multicolumn{3}{|c}{} \\
\hline
\end{tabular}

Sumber : Hasil Perhitungan.

Tabel 3. Hitungan Parameter Statistik untuk Distribusi Log Normal dan Log Pearson III

\begin{tabular}{|c|c|c|c|c|c|}
\hline No & Tahun & $\begin{array}{c}\mathrm{X} \\
(\mathrm{mm})\end{array}$ & $\log X$ & $\left(\log X_{i}-\overline{\log X}\right)^{2}$ & $\left(\log X_{i}-\overline{\log X}\right)^{3}$ \\
\hline 1 & 2015 & 68,90 & 1,840 & 0,0000 & 0,0000 \\
\hline 2 & 2016 & 20,94 & 1,321 & 0,2710 & $-0,1410$ \\
\hline 3 & 2017 & 74,20 & 1,870 & 0,0008 & 0,0000 \\
\hline 4 & 2018 & 145,5 & 2,163 & 0,1034 & 0,0333 \\
\hline 5 & 2019 & 103,0 & 2,013 & 0,0295 & 0,0051 \\
\hline \multicolumn{3}{|c|}{$\Sigma$} & $\begin{array}{l}9,207 \\
0,4047 \\
\end{array}$ & & $-0,1026$ \\
\hline
\end{tabular}

Sumber: Hasil Perhitungan.

Tabel 4. Perhitungan Perhitungan Nilai $x^{2}$ untuk Distribusi Normal

\begin{tabular}{|c|c|c|c|c|c|}
\hline Kelas & Interval & $\mathrm{E}_{\mathrm{f}}$ & $\mathrm{O}_{\mathrm{f}}$ & $\mathrm{O}_{\mathrm{f}}-\mathrm{E}_{\mathrm{f}}$ & $\frac{\left(O_{f}-O_{f}\right)^{2}}{E_{f}}$ \\
\hline 1 & $>121,081$ & 1 & 1 & 0 & 0 \\
\hline 2 & $93,988-121,081$ & 1 & 0 & 1 & 1 \\
\hline 3 & $71,028-93,988$ & 1 & 2 & -1 & 1 \\
\hline 4 & $43,9352-71,028$ & 1 & 1 & 0 & 0 \\
\hline 5 & $<43,9352$ & 1 & 1 & 0 & 0 \\
\hline & $\Sigma$ & 5 & 5 & $x^{2}$ & 2 \\
\hline
\end{tabular}

Sumber : Hasil Perhitungan.

Tabel 5. Perhitungan Perhitungan Nilai $x^{2}$ untuk Distribusi Log Normal

\begin{tabular}{|c|c|c|c|c|c|}
\hline Kelas & Interval & $\mathrm{E}_{\mathrm{f}}$ & $\mathrm{O}_{\mathrm{f}}$ & $\mathrm{O}_{\mathrm{f}}-\mathrm{E}_{\mathrm{f}}$ & $\frac{\left(O_{f}-O_{f}\right)^{2}}{E_{f}}$ \\
\hline 1 & $>128,83$ & & & & 0 \\
\hline 2 & $85,114-128,83$ & 1 & 1 & 0 & 0 \\
\hline 3 & $63,10-85,114$ & 1 & 1 & 0 & 0 \\
\hline 4 & $39,811-63,10$ & 1 & 1 & 0 & 0 \\
\hline 5 & $<39,811$ & 1 & 1 & 0 & 0 \\
\hline & $\Sigma$ & 5 & 5 & $x^{2}$ & 0 \\
\hline
\end{tabular}


Tabel 6. Perhitungan Perhitungan Nilai $x^{2}$ untuk Distribusi Gumbel

\begin{tabular}{|c|c|c|c|c|c|}
\hline Kelas & Interval & $\mathrm{E}_{\mathrm{f}}$ & $\mathrm{O}_{\mathrm{f}}$ & $\mathrm{O}_{\mathrm{f}}-\mathrm{E}_{\mathrm{f}}$ & $\frac{\left(O_{f}-O_{f}\right)^{2}}{E_{f}}$ \\
\hline 1 & $>135,95$ & & & & 0 \\
\hline 2 & $92,66-135,95$ & 1 & 1 & 0 & 0 \\
\hline 3 & $62,280-92,66$ & 1 & 1 & 0 & 0 \\
\hline 4 & $32,662-62,280$ & 1 & 2 & -1 & 1 \\
\hline 5 & $<32,662$ & 1 & 0 & 1 & 1 \\
\hline & $\Sigma$ & 5 & 5 & $x^{2}$ & 2 \\
\hline
\end{tabular}

Sumber : Hasil Perhitungan.

Tabel 7. Perhitungan Perhitungan Nilai $x^{2}$ untuk Distribusi Log Pearson III

\begin{tabular}{|c|c|c|c|c|c|}
\hline Kelas & Interval & $\mathrm{E}_{\mathrm{f}}$ & $\mathrm{O}_{\mathrm{f}}$ & $\mathrm{O}_{\mathrm{f}}-\mathrm{E}_{\mathrm{f}}$ & $\frac{\left(O_{f}-O_{f}\right)^{2}}{E_{f}}$ \\
\hline 1 & $>128,06$ & & & & 0 \\
\hline 2 & $85,114-128,06$ & 1 & 1 & 0 & 0 \\
\hline 3 & $79,433-85,114$ & 1 & 1 & 0 & 0 \\
\hline 4 & $75,86-79,433$ & 1 & 0 & 1 & 1 \\
\hline 5 & $<75,86$ & 1 & 2 & -1 & 1 \\
\hline & $\Sigma$ & 5 & 5 & $x^{2}$ & 2 \\
\hline
\end{tabular}

Sumber : Hasil Perhitungan.

Tabel 8. Uji Smirno-Kolmogorov Terhadap Distribusi Normal, Log Normal, Gumbel dan Log Pearson Type III

\begin{tabular}{|c|c|c|c|c|c|c|c|c|c|c|}
\hline \multirow{2}{*}{ No. } & \multirow{2}{*}{$\begin{array}{l}\text { Curah } \\
\text { Hujan }\end{array}$} & \multirow{2}{*}{$\mathrm{P}_{(\mathrm{E})} \%$} & \multicolumn{2}{|c|}{ Normal } & \multicolumn{2}{|c|}{ Log Normal } & \multicolumn{2}{|c|}{ Gumbel } & \multicolumn{2}{|c|}{ Log Pearson III } \\
\hline & & & $\mathrm{P}_{(\mathrm{T})}$ & $\Delta$ & $\mathrm{P}_{(\mathrm{T})}$ & $\Delta$ & $\mathrm{P}_{(\mathrm{T})}$ & $\Delta$ & $\mathrm{P}_{(\mathrm{T})}$ & $\Delta$ \\
\hline 1 & 20,94 & 16,6667 & 10,00 & 10,94 & 16,00 & 4,940 & 21,00 & 0,06 & 16,00 & 4,940 \\
\hline 2 & 68,90 & 33,3333 & 58,50 & 10,40 & 48,00 & 20,90 & 48,00 & 20,90 & 48,00 & 20,90 \\
\hline 3 & 74,20 & 50,0000 & 80,00 & 5,80 & 100,0 & 25,80 & 72,00 & 2,20 & 100,0 & 25,80 \\
\hline 4 & 103,0 & 66,6667 & 102,0 & 1,00 & 112,0 & 9,000 & 104,0 & 1,00 & 112,0 & 9,000 \\
\hline 5 & 145,5 & 83,3333 & 128,0 & 17,50 & 123,0 & 22,50 & 144,0 & 1,50 & 123,0 & 22,50 \\
\hline \multicolumn{3}{|c|}{$\Delta$ maks } & \multicolumn{2}{|c|}{$\begin{array}{l}\frac{17,5}{145,5} \times 100 \% \\
=12,03 \%\end{array}$} & \multicolumn{2}{|c|}{$\begin{array}{l}\frac{22,5}{145,5} \times 100 \% \\
=15,46 \%\end{array}$} & \multicolumn{2}{|c|}{$\begin{array}{l}\frac{1,5}{145,5} \times 100 \% \\
=1,031 \%\end{array}$} & \multicolumn{2}{|c|}{$\begin{aligned} & \frac{22,5}{145,5} \times 100 \% \\
= & 15,46 \%\end{aligned}$} \\
\hline
\end{tabular}

Sumber : Hasil Perhitungan.

Tabel 9. Uji Smirnov - Kolmogorov dan Chi - Kuadrat

\begin{tabular}{|c|c|c|c|c|c|c|c|}
\hline \multirow{2}{*}{ No. } & Distribusi & \multicolumn{3}{|c|}{ Chi - Kuadrat } & \multicolumn{3}{|c|}{ Uji Smirnov - Kolmogorov } \\
\cline { 3 - 8 } & & $x^{2}$ & $x^{2}$ cr & Keterangan & $\Delta$ maks & $\Delta_{\mathrm{CR}}$ & Keterangan \\
\hline 1 & Normal & 2 & 5,9910 & Diterima & $12,03 \%$ & $56 \%$ & Diterima \\
\hline 2 & Log Normal & 0 & 5,9910 & Diterima & $15,46 \%$ & $56 \%$ & Diterima \\
\hline $\mathbf{3}$ & Gumbel & $\mathbf{2}$ & $\mathbf{5 , 9 9 1 0}$ & Diterima & $\mathbf{1 , 0 3 1 \%}$ & $\mathbf{5 6 \%}$ & Diterima \\
\hline 4 & Log Pearson III & 2 & 5,9910 & Diterima & $15,46 \%$ & $56 \%$ & Diterima \\
\hline
\end{tabular}

Sumber : Hasil Perhitungan. 
JURNAL KACAPURI

JURNAL KEILMUAN TEKNIK SIPIL

Volume 4 Nomor 1 Edisi Juni 2021

Tabel 10. Perhitungan Koefisien Pengaliran $\left(\mathrm{C}_{\text {rata-rata }}\right)$ Daerah I

\begin{tabular}{|c|c|c|c|c|}
\hline Tata Guna & $\mathrm{Ci}$ & $\begin{array}{c}\mathrm{Ai} \\
(\mathrm{km})^{2}\end{array}$ & $\mathrm{Ci} \cdot \mathrm{Ai}$ & $\mathrm{C}=\frac{\sum_{i=1}^{n} C_{i} A_{i}}{\sum A_{i}}$ \\
\cline { 1 - 3 } Kebun & 0,30 & 0,376 & 0,1128 & 0,318 \\
\hline Padang rumput/semak-semak & 0,60 & 0,024 & 0,0144 & \\
\hline$\Sigma$ & & 0,4 & 0,1272 & \\
\hline
\end{tabular}

Sumber Ci : Hasil Perhitungan

Tabel 11. Perhitungan Koefisien Pengaliran $\left(\mathrm{C}_{\text {rata-rata }}\right)$

\begin{tabular}{|c|c|c|}
\hline Daerah Pengaliran & $\begin{array}{c}\text { A } \\
\left(\mathrm{Km}^{2}\right)\end{array}$ & C $_{\text {rata-rata }}$ \\
\hline Saluran Sekunder 1 & 0,4 & 0,318 \\
\hline Saluran Sekunder 2 & 0,4 & 0,324 \\
\hline Saluran Sekunder 3 & 0,4 & 0,321 \\
\hline Saluran Sekunder 4 & 0,4 & 0,327 \\
\hline Saluran Sekunder 5 & 0,4 & 0,327 \\
\hline
\end{tabular}

Sumber : Hasil Perhitungan

Tabel 12. Nilai Waktu Konsentrasi $\left(t_{c}\right)$ untuk Tiap Saluran

\begin{tabular}{|c|c|c|c|c|}
\hline No. & Daerah Pengaliran & $\begin{array}{c}\mathrm{L} \\
(\mathrm{Km})\end{array}$ & $\mathrm{S}$ & $\begin{array}{c}\mathrm{T}_{\mathrm{c}} \\
(\mathrm{Jam})\end{array}$ \\
\hline 1 & Saluran Sekunder 1 & 2,00 & 0,00303 & 1,0575 \\
\hline 2 & Saluran Sekunder 2 & 2,00 & 0,00305 & 1,0542 \\
\hline 3 & Saluran Sekunder 3 & 2,00 & 0,00310 & 1,0464 \\
\hline 4 & Saluran Sekunder 4 & 2,00 & 0,00310 & 1,0464 \\
\hline 5 & Saluran Sekunder 5 & 2,00 & 0,00303 & 1,0575 \\
\hline
\end{tabular}

Sumber : Hasil Perhitungan

Tabel 13. Nilai Intensitas Curah Hujan (I) untuk Tiap Saluran

\begin{tabular}{|c|c|c|c|c|}
\hline No & Daerah Pengaliran & $\begin{array}{c}\mathrm{X}_{\operatorname{Tr}} \\
(\mathrm{mm})\end{array}$ & $\begin{array}{c}\mathrm{T}_{\mathrm{c}} \\
(\mathrm{jam})\end{array}$ & $\begin{array}{c}\mathrm{I} \\
(\mathrm{mm} / \mathrm{jam})\end{array}$ \\
\hline 1 & Saluran Sekunder 1 & 135,95 & 1,0575 & 45,45 \\
\hline 2 & Saluran Sekunder 2 & 135,95 & 1,0542 & 45,55 \\
\hline 3 & Saluran Sekunder 3 & 135,95 & 1,0464 & 45,77 \\
\hline 4 & Saluran Sekunder 4 & 135,95 & 1,0464 & 45,77 \\
\hline 5 & Saluran Sekunder 5 & 135,95 & 1,0575 & 45,45 \\
\hline
\end{tabular}

Sumber : Hasil Perhitungan

Tabel 14. Nilai Debit Air Hujan Rencana $\left(Q_{a h}\right)$ untuk Tiap Saluran

\begin{tabular}{|c|c|c|c|c|c|}
\hline No & Daerah Pengaliran & $\mathrm{C}$ & $\begin{array}{c}\mathrm{I} \\
(\mathrm{mm} / \mathrm{jam})\end{array}$ & $\begin{array}{c}\mathrm{A} \\
\left(\mathrm{Km}^{2}\right)\end{array}$ & $\mathrm{Q}_{\text {ah }}\left(\mathrm{m}^{3} / \mathrm{det}\right)$ \\
\hline 1 & Saluran Sekunder 1 & 0,318 & 45,45 & 0,4 & 0,450 \\
\hline 2 & Saluran Sekunder 2 & 0,324 & 45,55 & 0,4 & 0,460 \\
\hline 3 & Saluran Sekunder 3 & 0,321 & 45,77 & 0,4 & 0,454 \\
\hline 4 & Saluran Sekunder 4 & 0,327 & 45,77 & 0,4 & 0,462 \\
\hline 5 & Saluran Sekunder 5 & 0,327 & 45,45 & 0,4 & 0,460 \\
\hline
\end{tabular}

Sumber : Hasil Perhitungan 
Tabel 15. Nilai Debit Drainase Rencana Kumulatif ( $\left.\mathrm{Q}_{\mathrm{r} \text { kum }}\right)$ untuk Tiap Saluran

\begin{tabular}{|c|c|c|c|c|}
\hline No. & Saluran & \multicolumn{3}{|c|}{$\begin{array}{l}\text { Debit Drainase Rencana Kumulatif } \\
\mathrm{Q}_{\mathrm{r} \text { kumulatif }}\left(\mathrm{m}^{3} / \mathrm{dt}\right)\end{array}$} \\
\hline 1 & Saluran $1\left(\mathrm{Q}_{\mathrm{s} 1}\right)$ & $\mathrm{Q}_{\mathrm{S} 1}$ & 0,450 & 0,450 \\
\hline 2 & Saluran $2\left(\mathrm{Q}_{\mathrm{s} 2}\right)$ & $\mathrm{Q}_{\mathrm{S} 1+} \mathrm{Q}_{\mathrm{S} 2}$ & $0,450+0,460$ & 0,910 \\
\hline 3 & Saluran $3\left(\mathrm{Q}_{\mathrm{s} 3}\right)$ & $\mathrm{Q}_{\mathrm{S} 1+} \mathrm{Q}_{\mathrm{S} 2+} \mathrm{Q}_{\mathrm{S} 3}$ & $0,450+0,460+0,454$ & 1,364 \\
\hline 4 & Saluran $4\left(\mathrm{Q}_{\mathrm{s} 4}\right)$ & $\mathrm{Q}_{\mathrm{r} 3}+\mathrm{Q}_{\mathrm{S} 4}$ & $1,364+0,462$ & 1,826 \\
\hline 5 & Saluran $5\left(Q_{s 5}\right)$ & $\mathrm{Q}_{\mathrm{r} 4+} \mathrm{Q}_{\mathrm{S} 5}$ & $1,826+0,460$ & 2,286 \\
\hline
\end{tabular}

Sumber : Hasil Perhitungan

Tabel 16. Kapasitas Drainase Untuk Tiap Saluran

\begin{tabular}{|c|c|c|c|c|c|c|c|c|c|c|c|}
\hline \multirow[t]{2}{*}{ No. } & \multirow[t]{2}{*}{ Daerah } & \multicolumn{4}{|c|}{ Dimensi Eksisting Saluran } & \multirow[t]{2}{*}{$\mathrm{m}$} & \multirow[t]{2}{*}{$\mathrm{n}$} & \multirow{2}{*}{$\begin{array}{c}\mathrm{A} \\
\left(\mathrm{m}^{2}\right)\end{array}$} & \multirow{2}{*}{$\begin{array}{l}\mathrm{P} \\
(\mathrm{m})\end{array}$} & \multirow{2}{*}{$\begin{array}{l}\mathrm{R} \\
(\mathrm{m})\end{array}$} & \multirow{2}{*}{$\begin{array}{c}\mathrm{Q}_{\mathrm{s}} \\
\left(\mathrm{m}^{3} / \mathrm{dt}\right)\end{array}$} \\
\hline & & $S$ & $\mathrm{~B}(\mathrm{~m})$ & $\mathrm{T}(\mathrm{m})$ & $\mathrm{h}(\mathrm{m})$ & & & & & & \\
\hline 1 & $\begin{array}{c}\text { Saluran } \\
\text { Sekunder 1 }\end{array}$ & 0,00303 & 2,50 & 4,0 & 1,70 & 1 & 0,02 & 7,14 & 7,13 & 0,980 & 19,39 \\
\hline 2 & $\begin{array}{c}\text { Saluran } \\
\text { Sekunder } 2\end{array}$ & 0,00305 & 2,60 & 4,0 & 1,70 & 1 & 0,02 & 6,72 & 7,13 & 0,943 & 17,77 \\
\hline 3 & $\begin{array}{c}\text { Saluran } \\
\text { Sekunder } 3\end{array}$ & 0,00310 & 2,20 & 4,0 & 1,70 & 1 & 0,02 & 6,08 & 6,73 & 0,803 & 14,71 \\
\hline 4 & $\begin{array}{c}\text { Saluran } \\
\text { Sekunder } 4\end{array}$ & 0,00310 & 2,20 & 4,0 & 1,70 & 1 & 0,02 & 6,08 & 6,73 & 0,803 & 14,71 \\
\hline 5 & $\begin{array}{c}\text { Saluran } \\
\text { Sekunder } 5\end{array}$ & 0,00303 & 2,50 & 4,0 & 1,70 & 1 & 0,02 & 7,14 & 7,31 & 0,980 & 19,39 \\
\hline
\end{tabular}

Sumber : Hasil Perhitungan

Tabel 17. Evaluasi Kapasitas Drainase untuk Tiap Saluran

\begin{tabular}{|c|c|c|c|c|c|}
\hline No. & Daerah & $\begin{array}{c}\mathrm{Q}_{\mathrm{s}} \\
\left(\mathrm{m}^{3} / \mathrm{det}\right)\end{array}$ & $\begin{array}{c}\mathrm{Q}_{\mathrm{r}} \\
\left(\mathrm{m}^{3} / \mathrm{det}\right)\end{array}$ & $\begin{array}{c}\text { Selisih } \\
\left(\mathrm{m}^{3} / \mathrm{det}\right)\end{array}$ & Keterangan \\
\hline 1 & Saluran 1 & 19,39 & 0,450 & 18,94 & Saluran Memadai \\
\hline 2 & Saluran 2 & 17,77 & 0,910 & 16,86 & Saluran Memadai \\
\hline 3 & Saluran 3 & 14,71 & 1,364 & 13,35 & Saluran Memadai \\
\hline 4 & Saluran 4 & 14,71 & 1,826 & 12,90 & Saluran Memadai \\
\hline 5 & Saluran 5 & 19,39 & 2,286 & 17,10 & Saluran Memadai \\
\hline
\end{tabular}

\section{PENUTUP}

\section{Kesimpulan}

Besarnya volume debit air pada sistem jaringan drainase yang dialirkan melalui saluran sekunder umur rencana 5 tahun $\left(\mathrm{X}_{\mathrm{TR}}=5\right.$ Tahun $)$ dengan menggunakan distribusi probalitas Gumbel adalah 135,95 mm, intensitas curah hujan 45,45 $\mathrm{mm} / \mathrm{jam}$. Pembuatan 25 saluran yang baru tidak perlu dan normalisasi 24 saluran yang lama dengan ketinggiaan air 1,70 m dari dasar saluran sudah cukup untuk mengatasi limpahan air pasang dari saluran PLG 1 juta hektar, 135,95 mm curah hujan. Dan ini dapat menghindari terjadinya banjir lagi dengan ketinggian $\pm 0,70$ $\mathrm{m}$. Adapun luas yang digenangi banjir pada saat ini berkisar \pm 320 hektar. Perencanaan saluran sekunder diambil debit aliran perhitungan yang terbesar 
yaitu $\mathrm{Q}=19,39 \mathrm{~m}^{3} / \mathrm{dt}>\mathrm{Qr}\left(\right.$ Debit drainase rencana kumulatif $\left.=2,286 \mathrm{~m}^{3} / \mathrm{dt}\right) \Rightarrow$ Ok.

Dimensi penampang pada 24 saluran sekunder yang lama dengan ukuran tabel dibawah ini :

\begin{tabular}{|c|c|c|c|c|c|c|c|c|c|c|c|}
\hline Daerah & \multicolumn{3}{|c|}{ Dimensi Eksisting Saluran } & $\mathrm{m}$ & $\mathrm{n}$ & $\begin{array}{c}\mathrm{A} \\
\left(\mathrm{m}^{2}\right)\end{array}$ & $\begin{array}{c}\mathrm{P} \\
(\mathrm{m})\end{array}$ & $\begin{array}{c}\mathrm{R} \\
(\mathrm{m})\end{array}$ & $\begin{array}{c}\mathrm{F} \\
(\mathrm{m})\end{array}$ & $\begin{array}{c}\mathrm{Q}_{\mathrm{s}} \\
\left(\mathrm{m}^{3} / \mathrm{dt}\right)\end{array}$ \\
\hline & $\mathrm{S}$ & $\mathrm{B}(\mathrm{m})$ & $\mathrm{T}(\mathrm{m})$ & $\mathrm{h}(\mathrm{m})$ & & & & & & & \\
\hline $\begin{array}{c}\text { Saluran } \\
\text { Sekunder } \\
1\end{array}$ & 0,00303 & 2,50 & 4,00 & 1,70 & 1,00 & 0,02 & 7,14 & 7,31 & 0,980 & 0,6 & 19,39 \\
$\mathrm{~h}$ & & & & & & & & & \\
\hline
\end{tabular}

\section{DAFTAR PUSTAKA}

1. Chow, V.T. 1992. Hindrolika Saluran Terbuka, Erlangga . Jakarta.

2. Departemen Pekerjaan Umum. 1986. Standar Perencanaan Irigasi. Galang Persada. Bandung.

3. Direktorat Jendral Bina Marga. 1990. Petunjuk Desain Drainase Permukaan Jalan.

4. Edwariansyah. 2008. Tugas Akhir Identifikasi Banjir dan Pengendaliannya pada Sistem Jaringan Drainase Perumahan Bukit Raya di Kota Sampit. Universitas Palangka Raya, Palangka Raya.

5. Firman, M Sahlana. 2005. Tugas Akhir Studi Evaluasi Sistem Drainase Pada Ruas Jalan Mayjen Sungkono Surabaya. Institut Teknologi Nasional. Malang.

6. Hindarko, 2000. Drainase Perkotaan. Es-HA, Yogyakarta.

7. Kamiana, I Made. 1987. Modul Kuliah Hidrologi. Universitas Palangka Raya, Palangka Raya.

8. Notodihardjo, Mardjono. 1998. Drainase perkotaan. Universitas Tarumanagara, Jakarta.

9. Pusat Penelitian dan Pengembangan Sumber Daya Air, Badan Penelitian dan Pengembangan Kimpraswil, Departemen Pekerjaan Umum. 2002. Kriteria Desain Bangunan Pengendalian Banjir. Pusat Penelitian dan Pengembangan Sumber Daya Air. Bandung.

10. Soemarto, C.D. 1987, Hidrologi Teknik. Usaha Nasional. Surabaya.

11. Soewarno, 1995. Aplikasi Metode Statistik Untuk Analisa Data Hidrologi Jilid II. Nova, Bandung.

12. Subarkah, Imam. 1978. Hidrologi Untuk Perencanaan Bangunan Air. Idea Dharma, Bandung.

13. Sunggono, V. 1984. Buku Teknik Sipil. Nova. Bandung.

14. Suripin. 2004. Sistem drainase Perkotaan yang berkelanjutan. Andi. Yogyakarta.

15. Triatmodjo, Bambang. 2008. Hidrologi Terapan. Beta Offset. Yogyakarta.

16. http://www.air.bappenas.go.id 